\title{
Superficial Papular Neuroma: Case Series of a New Entity R2
}

Stephanie J.T. Chen ${ }^{1}$, Rajiv M. Patel ${ }^{1,2}$, Christine P. Hans ${ }^{3}$, May P. Chan ${ }^{1,2}$ and Douglas R. Fullen ${ }^{1,2}$ Departments of Pathology ${ }^{1}$ and Dermatology ${ }^{2}$, University of Michigan, Ann Arbor, MI Department of Pathology ${ }^{3}$, Methodist Health System, Omaha, NE

Corresponding author:

Douglas R. Fullen, M.D.

UMHS Dept. of Pathology

3261 Med Sci I

1301 Catherine Street

Ann Arbor, MI 48109-5602

Email: dfullen@med.umich.edu

Phone: 734-764-4460

Fax: $734-764-4690$

\section{Abstract}

Background: Dermal neural lesions arise in various circumstances and may be difficult to classify.

Methods: We describe the clinical, histopathologic and immunophenotypic features of a series of

terminally-differentiated neural lesions not described previously, to our knowledge.

Results: Four cases from men aged 58-66 years were included. Some lesions reportedly bled, but no

inciting trauma or prior biopsies were reported. None recurred after biopsy, with follow-up ranging

from 19 to 113 months. All lesions were papular, with vertically-oriented S100-positive spindled cells

and nerve fibers in the papillary dermis. Slight epidermal hyperplasia, dilated superficial thin-walled

vessels and minimal to mild inflammation were seen in each. Fibers were uniformly fine in three cases,

with slightly thicker central fibers in the fourth. Three had parakeratotic scale. None were associated

with dermal fibrosis or adnexal proliferation. Neurofilament stained axons in each. EMA was negative

in all cases. CD34, melan-A and HMB45 were negative when performed.

This is the author manuscript accepted for publication and has undergone full peer review but has not been through the copyediting, typesetting, pagination and proofreading process, which may lead to differences between this version and the Version of Record. Please cite this article as doi: $10.1111 /$ cup.12981

This article is protected by copyright. All rights reserved. 
Conclusions: We report a small series of benign neural lesions and propose the name "superficial papular neuroma" for this distinct entity. Awareness is important to understand the clinical significance of these lesions and avoid misinterpretation that could lead to overtreatment, unnecessary work-up and increased cost.

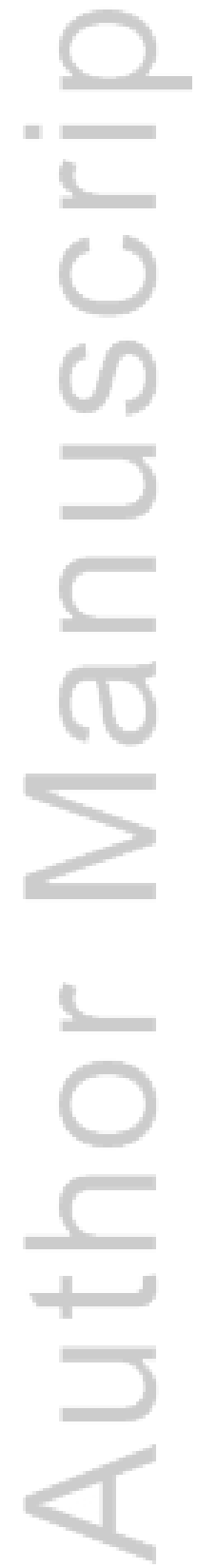

This article is protected by copyright. All rights reserved. 

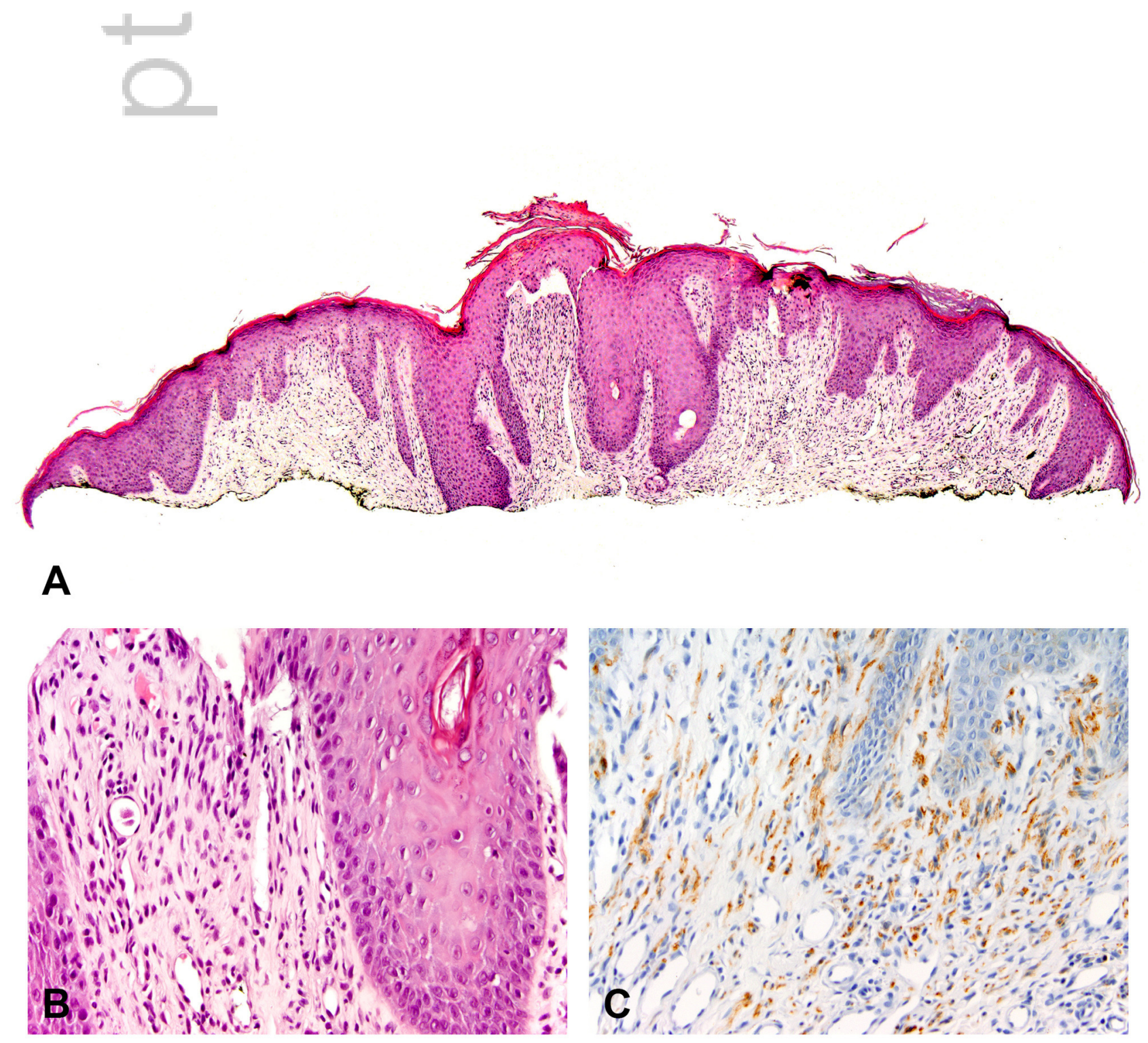

Fig1.jpg

This article is protected by copyright. All rights reserved. 

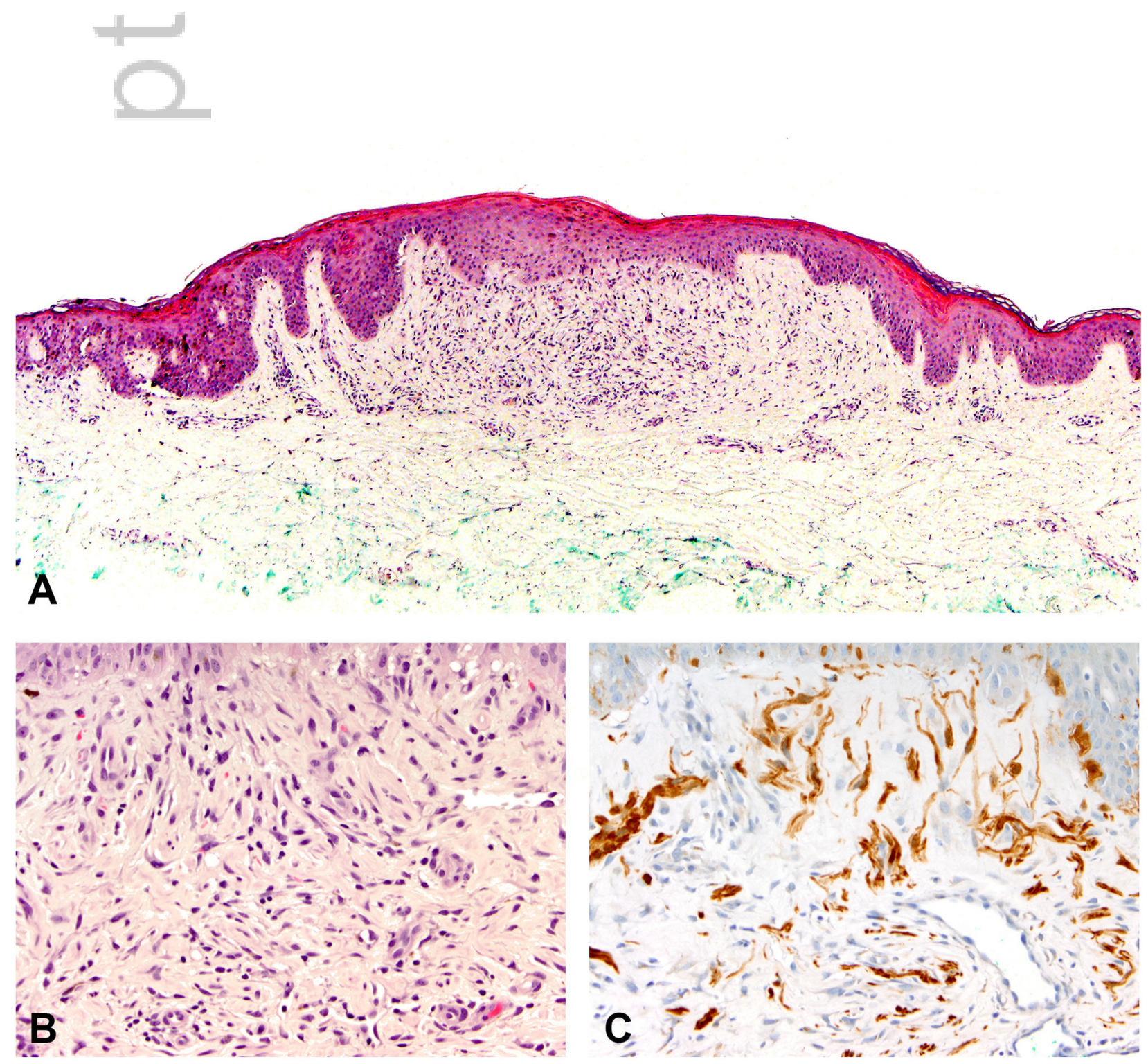

Fig2.jpg 

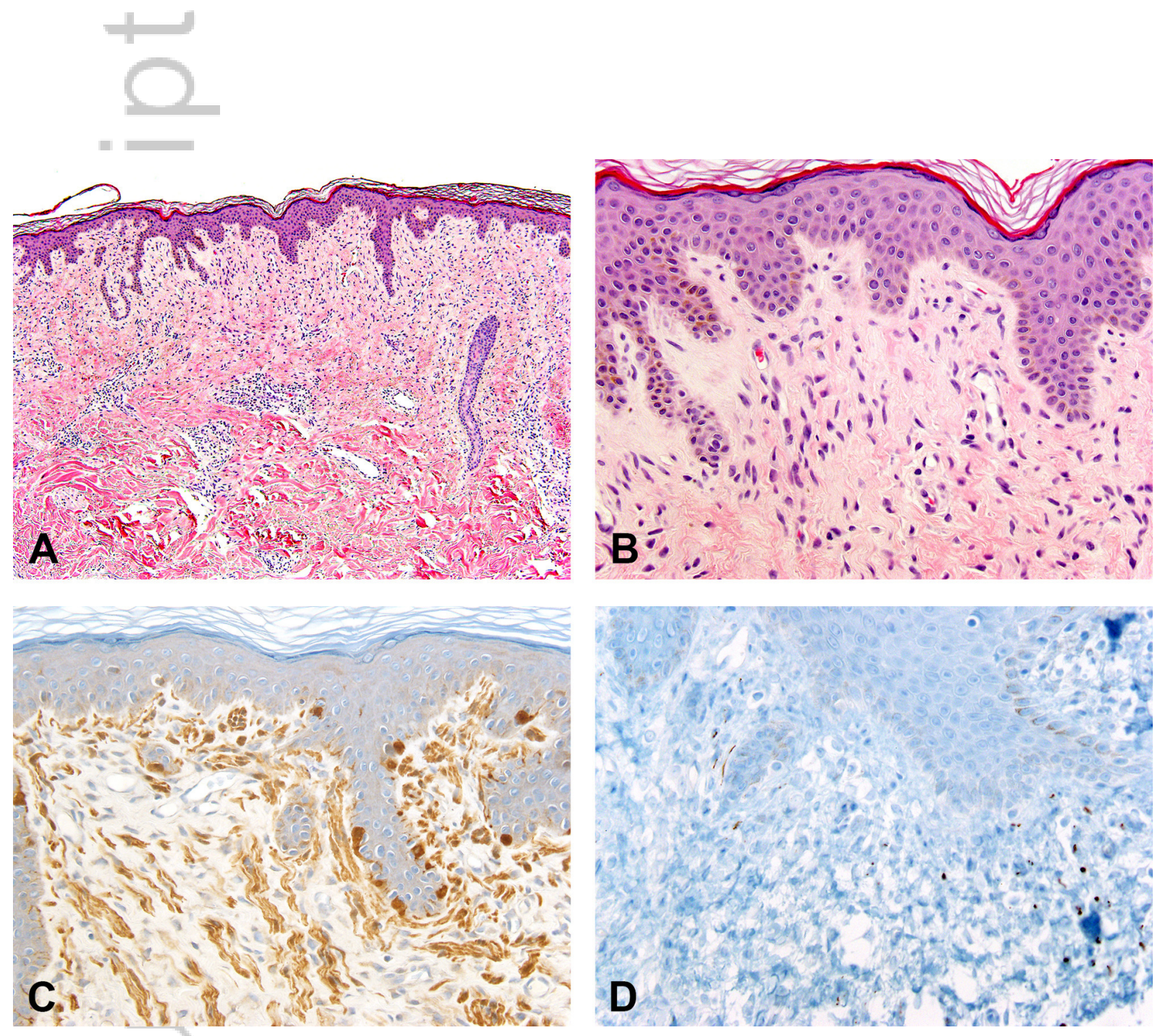

Fig3.jpg

This article is protected by copyright. All rights reserved. 


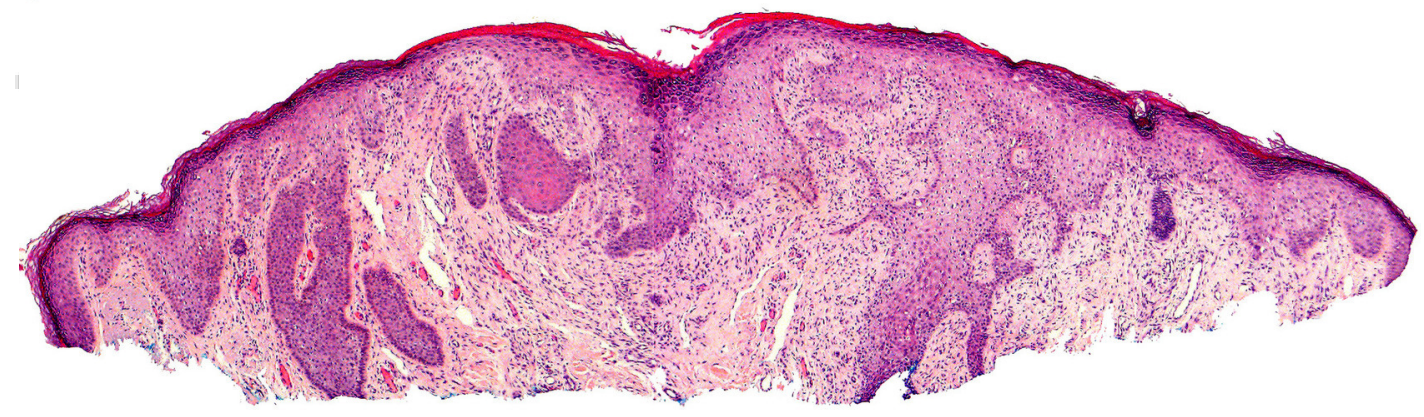

A
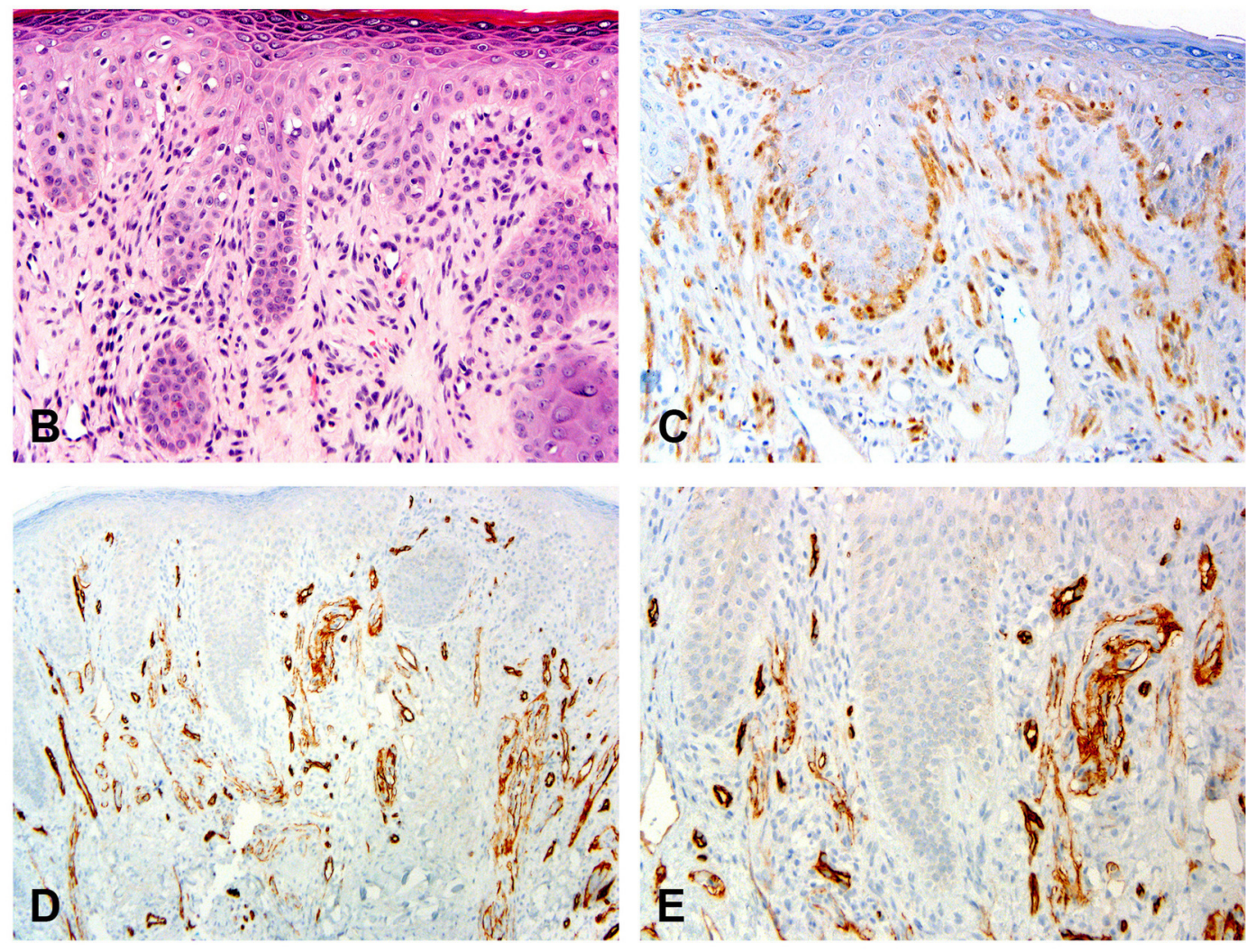

Fig4.jpg 


\section{Introduction}

Dermal lesions with neural differentiation may arise in a variety of circumstances, including as a response to injury, as a hamartomatous process or as a neoplasm. Although most dermal lesions with neural differentiation are classifiable using well-established diagnoses, some are not. As a consequence, several new entities have been reported in the last decade.(1-3)

We describe the clinical features and histopathologic and immunohistochemical findings in a series of four difficult to classify, terminally-differentiated neural lesions in the superficial dermis that, to our knowledge, have not been described previously. Recognition of this entity is important for future understanding of the clinical significance of such lesions and to avoid misdiagnosis, particularly as a melanocytic lesion or a neural lesion with syndromic associations.

\section{Materials and Methods}

The study was approved by the institutional review board. After receiving the index case (case 1) in consultation, the institutional files from January 2000 through December 2012 were retrospectively queried using the following search terms: "neuroma", "hamartoma" and "neurotized nevus." This search identified one additional morphologically similar, unclassifiable superficial dermal neural lesion (case 2). Two additional cases were prospectively collected from the consultative (case 3 ) and institutional (case 4) services. Patient demographics and clinicopathologic data were retrieved from medical records and contributing physicians.

Hematoxylin and eosin (H\&E) stained sections of three shave biopsies (cases 1-2 and 4) and one

excision (case 3) were evaluated for the following features: parakeratosis, epidermal hyperplasia, location of the lesion within the dermis, orientation and thickness of nerve fibers and the presence or absence of associated blood vessels, inflammation, dermal fibrosis or adnexal epithelium. Immunohistochemistry was performed at our institution on 4-micron thick formalin-fixed, paraffinembedded tissue sections using the BenchMark ULTRA (Ventana Medical Systems, Tucson, AZ) slide 
staining platform according to standard protocols validated in our immunoperoxidase laboratory. Each case was incubated with some or all of the following primary antibodies: S100 (predilute; rabbit polyclonal; Ventana Medical Systems), neurofilament (predilute; mouse monoclonal, clone 2F11; Cell Marque, Rocklin, CA), EMA (predilute; mouse monoclonal, clone E29; Ventana Medical Systems) and CD34 (1/100; mouse monoclonal, clone QBEnd 10; Dako, Glostrup, Denmark). Brown staining for protein expression was developed using the ultraView Universal DAB Detection Kit (Ventana Medical Systems), with hematoxylin as a counterstain. Appropriate in-lab controls were performed. For case 1, immunohistochemical stains for HMB45, melan-A and CD34 were performed at an outside institution and submitted for review. H\&E and immunostain sections from cases 2-4 were examined by four authors (SJTC, RMP, MPC, DRF) and sections from case 1 were examined by all authors.

H\&E stained sections of thirty-two sequential neurofibromas from the institutional files were reviewed by three authors (DRF, MPC, SJC) to assess the orientation of spindled cells and for features of irritation.

\section{Results}

Clinical data were available for all patients and are summarized in Table 1. Patients' ages ranged from 58 to 66 (average 61) years and all were men. One lesion (case 4) was present for 15 years, while the others were present for an unknown duration. All patients denied a history of trauma or biopsy at or near the site of the lesions before they developed. None of the patients had documented personal or family history of multiple endocrine neoplasia or neurofibromatosis. No lesions recurred, with follow-up ranging from 19 to 113 months.

One lesion (case 1) had a history of bleeding and another (case 4) was irritated with shaving. Both papules were fully developed prior to bleeding or irritation. The "lumpy" lesion in case 3 repeatedly fluctuated in size, per the patient. Each lesion was described as a solitary papule no greater 
than $5 \mathrm{~mm}$ in diameter. The lesion in case 2 was described as a depigmented papule in the center of a 6 mm brown macule. No other cases were associated with pigmentation.

Histopathologic features are summarized in Table 2. Histologic examination revealed a thin papular configuration in all lesions. Each showed spindled cells and vertically-oriented nerve fibers within the papillary dermis, abutting a slightly hyperplastic epidermis. The nerve fibers were uniformly fine in cases 1, 2 and 3 (Figures 1-3, respectively). In contrast, case 4 (Figure 4) retained fine fibers peripherally, but showed slightly thicker and more haphazardly arranged fibers centrally. Well-formed fascicles surrounded by perineurium were not observed in any of the cases. Dilated thin-walled blood vessels were noted in the superficial dermis of each lesion. Parakeratotic and hyperkeratotic scale surmounted the hyperplastic epidermis in cases 1-2 and 4. Case 3 did not have scale, but was associated with mild chronic superficial perivascular and periadnexal inflammation. Inflammation was minimal in cases 1-2. No cases were associated with dermal fibrosis or adnexal structures.

Immunohistochemical findings are summarized in Table 3. S100-positive single cells and fibers were associated with neurofilament-positive axons in each case. EMA was negative in all cases. CD34 performed on cases 1 and 4 (Figure 4D-E) highlighted small vessels and rare spindled cells arranged singly and focally in small aggregates within the lesion. The lesional cells in case 1 were negative for melan-A and HMB45.

Three of thirty-two (9.4\%) neurofibromas examined showed changes of irritation. None demonstrated the prominent vertical orientation of nerve fibers seen in our four cases.

\section{Discussion}

Dermal lesions consisting of spindled cells with neural differentiation may be difficult to characterize. Such lesions may represent a response to injury, a hamartomatous process or a true neoplasm. The cases presented here were diagnostically challenging. Each demonstrated similar 
reproducible clinical, histopathologic and immunohistochemical features, yet they were not diagnostic of a previously described entity.

Several hamartomatous entities were considered in the differential diagnosis. These included trichodiscoma, neurofollicular hamartoma and cutaneous solitary neural hamartoma. Trichodiscoma is characterized by a central proliferation of bland CD34-positive spindled cells surrounded by loose connective tissue stroma and encircled by a folliculosebaceous collarette. S100-positive nerve fibers have been described at the periphery of these lesions. $(4,5)$ A proliferation of small vessels, many with thick walls, may also be seen.(6) Neurofollicular hamartoma is a lesion composed of both mesenchymal and epithelial elements considered by some to be a spindle cell predominant variant of trichodiscoma. $(7,8)$ In neurofollicular hamartoma, haphazard fascicles of spindled cells with scattered S100-positivity comprise the stromal component, while distorted and hyperplastic pilosebaceous structures represent the epithelial component. $(9,10)$ The cases in our series are distinct from neurofollicular hamartoma and trichodiscoma in their more organized nerve fiber arrangement, lack of pilosebaceous abnormalities or hyperplasia and strong diffuse S100 staining.

Cutaneous solitary neural hamartoma is described as an unencapsulated nodule of haphazardly arranged, thick nerve fascicles in a periadnexal distribution, within the papillary and reticular dermis. These thick nerve bundles are S100 positive, contain neurofilament-positive axons and are surrounded by EMA-positive perineurium.(2) Unlike the nerve fascicles in cutaneous solitary neural hamartoma, the fibers in our series were smaller, vertically-oriented, mostly confined to the papillary dermis and lacked a periadnexal distribution. Moreover, the fibers lacked perineurium as evidenced by lack of EMA staining.

Another diagnostic consideration was neurofibroma. Sporadic neurofibromas are unencapsulated dermal proliferations of loosely arranged spindled cells with indistinct cytoplasm set in a collagenous, fibrillar, or myxoid stroma, often with conspicuous mast cells, and separated from the 
epidermis by a grenz zone.(4, 5) Immunohistochemical stains for S100, factor XIIla, neurofilament, GFAP and CD34 may all be positive. In neurofibromas, CD34 stains a variable but typically significant number of spindled to dendritic cells with oval to round nuclei.(11-13) These CD34-positive cells may be scattered or aggregated around vessels, adnexae or the periphery of tumors.(12) The neural lesions in our series were distinct from neurofibroma in that there is striking vertical orientation of individual nerve fibers, subepidermal distribution of these fibers without a grenz zone, absence of a characteristic stroma and lack of significant CD34 staining. Due to the presence of epidermal hyperplasia and parakeratosis, we considered the possibility that these lesions might represent irritation changes in neurofibromas. However, none of the irritated neurofibromas we reviewed demonstrated the prominent vertical nerve fiber orientation seen in our cases. Although the number of reviewed irritated neurofibromas was relatively small, given the frequency of irritation changes in neurofibromas, one would expect to encounter the histopathologic findings described in this series more frequently in clinical practice if they truly represented irritated neurofibromas.

Solitary circumscribed neuroma, also known as palisaded encapsulated neuroma, is a wellcircumscribed lesion composed of short nerve fascicles surrounded by a discontinuous, EMA-positive capsule.(4-6) Although previously considered a nerve sheath tumor, some suggest that solitary circumscribed neuroma is regenerative in nature given its ultrastructural resemblance to traumatic neuroma.(14) The cases presented here lacked the circumscription and discontinuous EMA-positive perineurial capsule characteristic of solitary circumscribed neuroma.

Previously described reactive entities were also excluded from the differential diagnosis. Traumatic neuroma is characterized by a well-defined, but unencapsulated mass of haphazardly arranged S100-positive nerve fascicles. Each fascicle is surrounded by EMA-positive perineurium and embedded in a fibrous scar.(4-6) In contrast, the vertical arrangement of the fine fibers, absence of discrete nerve bundles or associated perineurium, lack of dermal fibrosis and lack of prior biopsy or 
inciting trauma distinguished our cases from traumatic neuroma. Prurigo nodularis also entered our differential diagnosis due to the reported history of irritation in some of our cases. Aside from the classic features of marked epidermal acanthosis, hyperkeratosis, increased small dermal blood vessels and vertically-oriented dermal collagen, several authors have also documented nerve fiber hyperplasia and hypertrophy in prurigo nodularis.(15-17) Cowen described "nerve fibers which often passed directly towards the dermo-epidermal junction without taking a significant part in the cutaneous nerve plexus" and small aggregates of Schwann cells just below the dermo-epidermal junction.(15) Runne and Orfanos described nerve fiber disorientation or "axonal seas", while Hirschel-Scholz et al. made no mention of nerve fiber orientation in their cases.(16-17) These variably-sized hyperplastic nerve fibers have been highlighted with immunohistochemical stains and identified in all layers of the dermis.(15-17) Recognition of such a neural proliferation on routine light microscopy, however, was seen in only $2.2 \%$ of 136 prurigo nodularis biopsies in a more recent series.(18) Finally, Mason et al. described hypertrophied and tortuous dermal nerves in the papillary and reticular dermis of a patient who presented with pain and pruritus in the absence of a clinically-apparent lesion. This patient showed no evidence of multiple endocrine neoplasia, type $2 b$ (MEN 2b), a syndrome associated with neural lesions as described below. The authors speculated the lesion likely occurred as a result of scratching or other trauma.(19) Our cases lacked the marked epidermal acanthosis and prominent dermal fibrosis characteristic of prurigo nodularis. Moreover, our cases demonstrated uniform vertical orientation of fine fibers, a feature not consistently noted in previous descriptions of nerve hypertrophy/hyperplasia in prurigo nodularis. Finally, the nerve trunks described in the case report by Mason et al. were much larger and lacked the prominent vertical orientation noted in our cases.

Unusual cutaneous neural lesions may be associated with neurofibromatosis (NF) or MEN 2b. NF 1 is classically associated with multiple cutaneous neurofibromas and café-au-lait macules, while schwannomas represent the most common cutaneous manifestation of NF 2.(4,6, 20) Pacinian 
corpuscle hypertrophy,(21) perineuriomas(22) and hybrid neural tumors(23) have also been documented in case reports of patients with NF. A study published in 2000 revealed a clinically occult neurofibroma and increased scattered S100-positive dermal cells in biopsies of clinically normal skin from five patients with NF 1.(24) In 1982, Winkelmann and Carney documented dermal hyperneury (increased number and size of nerve fascicles) in biopsies of clinically normal skin from seven patients with MEN 2b.(25) Dermal hyperneury has also been demonstrated in areas of linear pigmentation in a patient with marfanoid body habitus and possible limited MEN 2b.(26) All patients in our series presented with solitary and clinically apparent lesions and none had personal/family history or clinical features to suggest NF or MEN $2 b$, rendering a syndromic association highly unlikely.

Apart from neural lesions, melanocytic lesions may be considered when faced with an S100positive spindled cell proliferation in the superficial dermis. Desmoplastic melanoma is characterized by a dermal proliferation of spindled cells associated with a desmoplastic or myxoid stroma. Although the melanocytes in desmoplastic melanoma tend to be deceptively bland, occasional hyperchromatic and pleomorphic nuclei are often present. When present, overlying melanoma in situ and lymphocytic aggregates can serve as clues to the diagnosis in paucicellular cases. Clinical history is also useful, as desmoplastic melanoma most commonly occurs on sun-damaged skin. Several features argued against desmoplastic melanoma in our cases, including occurrence on sun-protected sites, lack of an overlying intraepidermal melanocytic proliferation, uniformly bland cytology of the S100-positive spindled cells and positive neurofilament staining in some of the spindled cells. Our cases were also distinguished from neurotized nevus by the lack of nested growth, the absence of type A or B melanocytes, the presence of dispersed neurofilament positive axons and the negative melan-A staining. $(4,27)$ In conclusion, we present a series of terminally-differentiated neural lesions with characteristic clinicopathologic features that, to our knowledge, have not been previously reported. The lesions are small papules with slight epidermal hyperplasia overlying a superficial dermal lesion consisting of 
vertically-oriented delicate nerve fibers associated with small, thin-walled blood vessels and without associated adnexal element. These lesions are benign and by history are not precipitated by trauma, although their pathoetiology is not entirely clear. These lesions appear most compatible with a type of neuroma and we propose the name "superficial papular neuroma" for this distinct entity. Awareness of this entity is important to appropriately classify such lesions and to avoid misinterpretation as a melanocytic lesion or a neural lesion with syndromic association that could lead to unnecessary work-up and increased cost.

\section{References}

1. Thareja S, Honigbaum A, and Jukic D. Glomus-like bodies within a neurofibroma: a novel neoplasm arising in neurofibromatosis type 1 or a coincidence? J Cutan Pathol 2015; 42: 285.

2. Al Habeeb A, Alkhalidi H, Idikio H, Ghazarian D. Cutaneous solitary neural hamartoma: report of an unusual case. Am J Dermatopathol 2009; 31: 484.

3. Weinreb I, Labonte S, Goli H, Chetty R, Ghazarian D. Cutaneous melanocytoneuroma: the first case of a distinctive intraneural tumor with dual nerve sheath and melanocytic differentiation. J Cutan Pathol 2007; 34 Suppl 1: 52.

4. Patterson JW. Weedon's skin pathology. $4^{\text {th }}$ ed. Elsevier Limited 2016.

5. Rodriguez-Peralto JL, Riveiro-Falkenbach E, Carrillo R. Benign cutaneous neural tumors. Semin Diagn Pathol 2013; 30: 45.

6. Calonje E, Brenn T, Lazar A, McKee PH, editors. McKee's pathology of the skin with clinical correlations. $4^{\text {th }}$ ed. Elsevier Limited/Saunders 2012.

7. Kutzner H, Requena L, Rutten A, Mentzel T. Spindle cell predominant trichodiscoma: a fibrofolliculoma/trichodiscoma variant considered formerly to be a neurofollicular hamartoma: a clinicopathological and immunohistochemical analysis of 17 cases. Am J Dermatopathol 2006; 28: 1.

8. Sangueza OP, Requena L. Neurofollicular hamartoma. A new histogenetic interpretation. Am J Dermatopathol 1994; 16: 150.

9. Barr RJ, Goodman MM. Neurofollicular hamartoma: a light microscopic and immunohistochemical study. J Cutan Pathol 1989; 16: 336.

10. Nova MP, Zung M, Halperin A. Neurofollicular hamartoma. A clinicopathological study. Am J - Dermatopathol 1991; 13: 459.

11. Weiss SW, Nickoloff BJ. CD-34 is expressed by a distinctive cell population in peripheral nerve, nerve sheath tumors, and related lesions. Am J Surg Pathol 1993; 17: 1039.

12. Caubal A, Paetau A, Zoltick P, Miettinen M. CD34 immunoreactivity in nervous system tumors. Acta Neuropathol 1993; 88: 454.

13. Khalifa MA, Montgomery EA, Ismiil N, Azumi N. What are the CD34+ cells in benign peripheral nerve sheath tumors? Am J Clin Pathol 2000; 114: 123.

14. Dover JS, From L, Lewis A. Palisaded encapsulated neuromas. A clinicopathologic study. Arch Dermatol 1989; 125: 386.

15. Cowan MA. Neurohistological Changes in Prurigo Nodularis. Arch Dermatol 1964; 89: 754.

16. Runne $U$, Orfanos CE. Cutaneous neural proliferation in highly pruritic lesions of chronic prurigo. Arch Dermatol 1977; 113: 787. 
17. Hirschel-Scholz S, Salomon D, Merot Y, Saurat JH. Anetodermic prurigo nodularis (with Pautrier's neuroma) responsive to arotinoid acid. J Am Acad Dermatol 1991; 25: 437.

18. Weigelt N, Metze D, Stander S. Prurigo nodularis: systematic analysis of 58 histological criteria in 136 patients. J Cutan Pathol 2010; 37: 578.

19. Mason GH, Pitt TE, Tay E. Cutaneous nerve hypertrophy. Pathology 1998; 30: 422.

20. Mautner VF, Lindenau M, Baser ME, Kluwe L, Gottschalk J. Skin abnormalities in neurofibromatosis 2. Arch Dermatol 1997; 133: 1539.

21. Yan S, Horangic NJ, Harris BT. Hypertrophy of Pacinian corpuscles in a young patient with neurofibromatosis. Am J Dermatopathol 2006; 28: 202.

22. Ausmus GG, Piliang MP, Bergfeld WF, Goldblum JR. Soft-tissue perineurioma in a 20-year-old patient with neurofibromatosis type 1 (NF1): report of a case and review of the literature. J Cutan Pathol 2007; 34: 726.

23. Feany MB, Anthony DC, Fletcher CD. Nerve sheath tumours with hybrid features of neurofibroma and schwannoma: a conceptual challenge. Histopathology 1998; 32: 405.

24. Karvonen SL, Kallioinen M, Yla-Outinen H, Poyhonen M, Oikarinen A, Peltonen J. Occult neurofibroma and increased S100 protein in the skin of patients with neurofibromatosis type 1: new insight to the etiopathomechanism of neurofibromas. Arch Dermatol 2000; 136: 1207.

25. Winkelmann RK, Carney JA. Cutaneous neuropathology in multiple endocrine neoplasia, type $2 b$. J Invest Dermatol 1982; 79: 307.

26. Guillet G, Gauthier Y, Tamisier JM, et al. Linear cutaneous neuromas (dermatoneurie en stries): a limited phakomatosis with striated pigmentation corresponding to cutaneous hyperneury (featuring multiple endocrine neoplasia syndrome?). J Cutan Pathol 1987; 14: 43.

27. Chen Y, Klonowski PW, Lind AC, Lu D. Differentiating neurotized melanocytic nevi from neurofibromas using Melan-A (MART-1) immunohistochemical stain. Arch Pathol Lab Med 2012; 136: 810 .

This article is protected by copyright. All rights reserved. 
Table 1. Clinical data

\begin{tabular}{|c|c|c|c|c|}
\hline & Case 1 & Case 2 & Case 3 & Case 4 \\
\hline Age (years) & 58 & 62 & 66 & 58 \\
\hline Gender & M & M & M & M \\
\hline History of MEN or NF & No & No & No & No \\
\hline Duration of lesion & Unknown & Unknown & Unknown & 15 years \\
\hline $\begin{array}{l}\text { Prior biopsy or reported } \\
\text { inciting trauma }\end{array}$ & No & No & No & No \\
\hline Location & L temple & R upper back & Back & Chin \\
\hline Clinical appearance & $2 \mathrm{~mm}$ papule & $\begin{array}{l}6 \text { mm brown } \\
\text { macule with } \\
\text { central } 2 \mathrm{~mm} \\
\text { depigmented } \\
\text { erythematous, } \\
\text { perifollicular } \\
\text { papule }\end{array}$ & $\begin{array}{l}5 \mathrm{~mm} \text { lumpy } \\
\text { lesion }\end{array}$ & $\begin{array}{l}\text { Size not given } \\
\text { pink papule }\end{array}$ \\
\hline Clinical impression & $\begin{array}{l}\text { BCC, nevus, } \\
\text { irritated SK }\end{array}$ & $\begin{array}{l}\text { Atypical nevus, } \\
\text { nevus with } \\
\text { inflamed hair } \\
\text { follicle }\end{array}$ & Cyst & Nevus, cyst \\
\hline Procedure & Shave & Shave & Excision & Shave \\
\hline
\end{tabular}

M, male; MEN, multiple endocrine neoplasia; NF, neurofibromatosis; L, left; R, right; BCC, basal cell carcinoma; SK, seborrheic keratosis. 
Table 2. Histopathologic features

\begin{tabular}{lllll}
\hline & Case 1 & Case 2 & Case 3 & Case 4 \\
\hline Location & Papillary dermis & Papillary dermis & Papillary dermis & Papillary dermis \\
Epidermal hyperplasia & Slight & Slight & Slight & Slight \\
Hyperparakeratotic scale & Yes & Yes & No & Yes \\
Nerve fibers & $\begin{array}{l}\text { Fine, vertically- } \\
\text { oriented }\end{array}$ & $\begin{array}{l}\text { Fine, vertically- } \\
\text { oriented }\end{array}$ & $\begin{array}{l}\text { Fine, vertically- } \\
\text { oriented }\end{array}$ & Slightly thicker, \\
vuperficial, dilated, thin- & Yes & Yes & Yes & Yes \\
$\begin{array}{l}\text { walled vessels } \\
\text { Chronic inflammation }\end{array}$ & $\begin{array}{l}\text { Minimal, } \\
\text { perivascular }\end{array}$ & Minimal, & perivascular & Mild, perivascular \\
and periadnexal & Mild,focal \\
Dermal fibrosis & No & No & No & No \\
Adnexal proliferation & No & No & No & No \\
\hline
\end{tabular}

This article is protected by copyright. All rights reserved. 
Table 3. Immunohistochemical staining

\begin{tabular}{lllll}
\hline & Case 1 & Case 2 & Case 3 & Case 4 \\
\hline S100 & + & + & + & + \\
Neurofilament & + & + & + & + \\
EMA & - & - & - & - \\
HMB-45 & $-{ }^{\mathrm{b}}$ & $\mathrm{NP}$ & $\mathrm{NP}$ & $\mathrm{NP}$ \\
Melan-A & $-{ }^{\mathrm{b}}$ & $\mathrm{NP}$ & $\mathrm{NP}$ & NP \\
CD34 & Rare $^{\mathrm{a}, \mathrm{b}}$ & $\mathrm{NP}$ & $\mathrm{NP}$ & Rare $^{\text {a }}$ \\
\hline
\end{tabular}

${ }^{a}$ CD34 stained thin-walled vessels and rare spindled cells arranged singly and in focal small aggregates in the superficial dermis; ${ }^{b}$ stains performed at outside institution; NP, not performed.
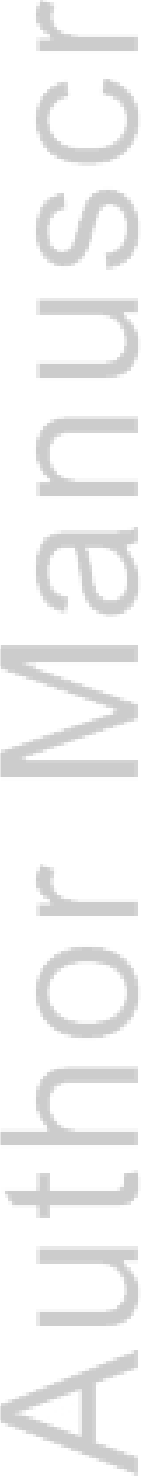

This article is protected by copyright. All rights reserved. 
Figure 1. Case 1, a $2 \mathrm{~mm}$ papule on a 58-year-old male's left temple. A, Shave biopsy shows a papule with slight epidermal hyperplasia and overlying hyperparakeratotic scale. B, Fine, vertically-oriented fibers in the superficial dermis abut the overlying epidermis and are associated with dilated thin-walled vessels. C, An S100 immunostain highlights the vertical orientation of fibers (hematoxylin and eosin, original magnifications X40 [A] and X400 [B]; S100, original magnification X400 [C]).

Figure 2. Case 2, a brown macule with central $2 \mathrm{~mm}$ depigmented papule on a 62-year-old male's upper back. A, Shave biopsy shows a small papule with slight overlying epidermal hyperplasia. B, Fine, vertically-oriented fibers abut the epidermis. C, An S100 immunostain highlights the vertical orientation of nerve fibers, adjacent to thin-walled, dilated vessels (hematoxylin and eosin, original magnifications $\mathrm{X} 40[\mathrm{~A}]$ and X400 [B]; S100, original magnification X400 [C]).

Figure 3. Case 3, a $5 \mathrm{~mm}$ lumpy lesion on a 66-year-old male's back. A, Excisional biopsy demonstrates a papule formed by a subtle superficial dermal proliferation associated with slight epidermal hyperplasia, focal scale, and dilated thin-walled vessels. B, Fine, vertically-oriented fibers in the superficial dermis abut the overlying epidermis. C, An S100 immunostain demonstrates the vertical orientation of fibers, while neurofilament stains axons in panel D (hematoxylin and eosin, original magnifications X40 [A] and X400 [B]; S100, original magnification X400 [C]; neurofilament, original magnification X400 [D]).

Figure 4. Case 4, a pink papule on a 58-year-old male's chin. A, Shave biopsy shows a small papule with slight overlying epidermal hyperplasia and parakeratotic scale. B, Fine, vertically-oriented fibers in the papillary dermis abut the epidermis. C, An S100 immunostain demonstrates the vertical orientation of fibers. D, CD34 stains small vessels in addition to rare spindled cells arranged singly and in focal small aggregates in panel E (hematoxylin and eosin, original magnifications X40 [A] and X200 [B]; S100, original magnification X200 [C]; CD34, original magnification X100 [D] and X200 [E]). 